\title{
Occurrence of a New Subclade of Leptosphaeria biglobosa in Western Australia
}

\author{
L. Vincenot, M. H. Balesdent, H. Li, M. J. Barbetti, K. Sivasithamparam, L. Gout, and T. Rouxel
}

First, second, sixth, and seventh authors: INRA, UMR 1290 (BIOGER-CPP), Route de Saint Cyr, 78026 Versailles Cedex, France; third and fifth authors: School of Earth and Geographical Sciences; fourth author: School of Plant Biology, Faculty of Natural and Agricultural Sciences, The University of Western Australia, Crawley, WA 6009, Australia; sixth author: AgroParisTech, Protection des Plantes, 78850 Thiverval Grignon, France.

Accepted for publication 1 November 2007.

\begin{abstract}
Vincenot, L., Balesdent, M. H., Li, H., Barbetti, M. J., Sivasithamparam, K., Gout, L., and Rouxel, T. 2008. Occurrence of a new subclade of Leptosphaeria biglobosa in Western Australia. Phytopathology 98:321329.

Stem canker of crucifers is caused by an ascomycete species complex comprising of two main species, Leptosphaeria maculans and L. biglobosa. These are composed of at least seven distinct subclades based on biochemical data or on sequences of internal transcribed spacer (ITS), the mating type MAT1-2 or fragments of actin or $\beta$-tubulin genes. In the course of a wide-scale characterization of the race structure of L. maculans from Western Australia, a few isolates from two locations failed to

isolates were classified as belonging to the L. biglobosa species. Parsimony and distance analyses performed on ITS, actin and $\beta$-tubulin sequences revealed that these isolates formed a new L. biglobosa subclade, more related to the Canadian L. biglobosa 'canadensis' subclade than to the L. biglobosa 'australensis' isolates previously described in Australia (Victoria). They are termed here as L. biglobosa 'occiaustralensis'. These isolates were mainly recovered from resistant oilseed rape cultivars that included the Brassica rapa sp. sylvestris-derived resistance source, but not from the susceptible cv. Westar. The pathogenicity of L. biglobosa 'occiaustralensis' to cotyledons of most oilseed rape genotypes was higher than that of L. biglobosa 'canadensis' or L. biglobosa 'australensis' isolates.
\end{abstract} amplify specific sequences of $L$. maculans, i.e., the mating-type or minisatellite alleles. Based on both pathogenicity tests and ITS size, these

Fungal diseases of plants are often caused by (or associated with) a species complex of more or less closely related fungal species (21). A species complex encompassing two closely related Dothideomycete species, Leptosphaeria maculans and L. biglobosa, is associated with the most damaging disease of oilseed rape/canola (Brassica napus), the stem canker disease (also termed Blackleg disease) $(9,15)$. These two species are usually difficult to distinguish using conventional morphological criteria, and only could accurately be discriminated with the advent of molecular tools (21). However, even though sharing similar epidemiology, identical infection strategies, and the same ecological niche, being often found together in the tissues of individual infected plants, their incidence in terms of disease expression and disease severity is often very different $(28,30)$. Briefly, the primary symptoms caused by $L$. maculans on leaves of B. napus in the field are typical large pale brown, pale gray, or greyish green lesions, whereas L. biglobosa only causes small dark lesions that may be confused with other symptoms such as those from Alternaria leaf spots. At a later stage, following systemic colonization of plant tissues, L. maculans isolates cause the damaging basal stem canker (crown canker), whereas L. biglobosa isolates cause pale brown lesions with a dark margin on the upper stem (termed Phoma or upper stem lesions). Finally, L. maculans isolates were shown to be highly specialized pathogens developing gene-forgene interactions with all their Brassica hosts (B. napus, B. rapa, $B$. oleracea, and B. juncea, etc.) (3). In contrast, such specialized interactions were never observed to date in the L. biglobosa

Corresponding author: M. H. Balesdent; E-mail address: mhb@versailles.inra.fr

doi:10.1094/PHYTO-98-3-0321

(C) 2008 The American Phytopathological Society
Additional keywords: blackleg disease, B. napus, Phoma lingam.

isolates which seem to be equally capable (or incapable) of causing symptoms on all crucifer species (10). However, this latter point has not been investigated in detail due to the low effect of $L$. biglobosa on yield in most countries.

According to the literature, one additional dissimilarity between L. maculans and L. biglobosa regards their geographic distribution. Whereas both species are widely distributed worldwide, there are indications that L. maculans is a currently expanding species that historically colonized countries where L. biglobosa was prevalent, such as Poland and Central Canada $(9,21)$. The current lack of occurrence of L. maculans in countries such as China $(9,29)$ may only be a reflection of limited sampling and surveys. However, despite extensive samplings and surveys, only three records suggest the occurrence of L. biglobosa in Australia $(12,20,24)$.

The postulate that L. maculans is a younger expanding species is strongly substantiated by molecular phylogeny studies, either using internal transcribed spacer (ITS) sequences or multipleencoding genes, which both revealed that L. maculans is a highly monomorphic species, whereas the L. biglobosa species encompasses five distinct subclades $(15,27)$. The most common one, L. biglobosa 'brassicae', is found in most oilseed rape growing regions of the world except Central Canada and Australia, and is closely associated with $L$. maculans on oilseed rape plants. The other subclades are often represented by a low number of isolates in international collections, such as the IBCN (International Blackleg of Crucifers Network) collection. Such is the case for the six L. biglobosa 'canadensis' isolates analyzed, predominantly originating from $B$. napus or $B$. juncea crops, but also from cruciferous weeds such as Thlaspi arvense in Central Canada (Saskatchewan), the three L. biglobosa 'thlaspii' isolates originating from $T$. arvense in Central Canada, the unique L. biglobosa 
'erysimii' obtained from the cruciferous weed Erysimum sp. in Central Canada, and the three L. biglobosa 'australensis' isolates obtained from $B$. napus or B. oleracea and originating from the United States or Victoria (Australia) $(15,27)$. The phylogenetic analysis of multiple protein-encoding genes was finally used to suggest an evolutionary series in the L. maculans-L. biglobosa species complex, with L. biglobosa 'australensis' and 'erysimii' being the possible ancestors to the whole L. biglobosa clade, and L. biglobosa 'thlaspii' being the closest relative to L. maculans (27).

In the course of a 2003 to 2005 sampling campaign aiming at characterization of races of $L$. maculans occurring on canola in Western Australia, a few isolates showed morphological, biological, and molecular traits reminiscent of L. biglobosa (28). A re-examination of isolates in the University of Western Australia collection allowed us to find additional isolates with similar traits. The aim of this paper is to characterize in detail these atypical isolates. Phylogenetic analyses of ITS sequences and $\beta$-tubulin and actin-encoding genes were performed, and suggested these isolates belong to a new subclade of L. biglobosa. Finally, their pathogenicity was analyzed to evaluate their aggressiveness and host specificity towards a range of oilseed rape genotypes.

\section{MATERIALS AND METHODS}

Fungal strains and culture maintenance. From a total of 188 isolates recovered from oilseed rape or cruciferous weeds in Western Australia, 19 isolates showing atypical morphological, pathological, and molecular characteristics were analyzed in detail in this study. These 19 isolates were discriminated from L. maculans by morphological traits reminiscent of $L$. biglobosa (28), failure in polymerase chain reaction (PCR) amplification of L. maculans specific sequences, (i.e., the mating-type and MinLm1-MinLm6 loci) $(8,11)$, and L. biglobosa-like pathogenicity following inoculation on cotyledons of oilseed rape (10) (Fig. 1). These 19 isolates originated from two locations, Wongan Hills ( 8 isolates) and Mount Barker (11 isolates). They were obtained in three consecutive years (2002 to 2004). They were either (i) single-ascospore isolates obtained from infected stems of the 'sylvestris'-derived resistance-harboring cvs. Surpass 501TT or Surpass 404CL ( 8 isolates), of cv. Grouse (Rlm3) (1 isolate), or of wild radish, Raphanus raphanistrum (1 isolate), or (ii) single conidium isolates obtained in 2002 or 2003 at Mount Barker from leaves of cv. Hyola $60(R \operatorname{lml})$ (4 isolates) and wild radish (5 isolates) (Table 1$)$.

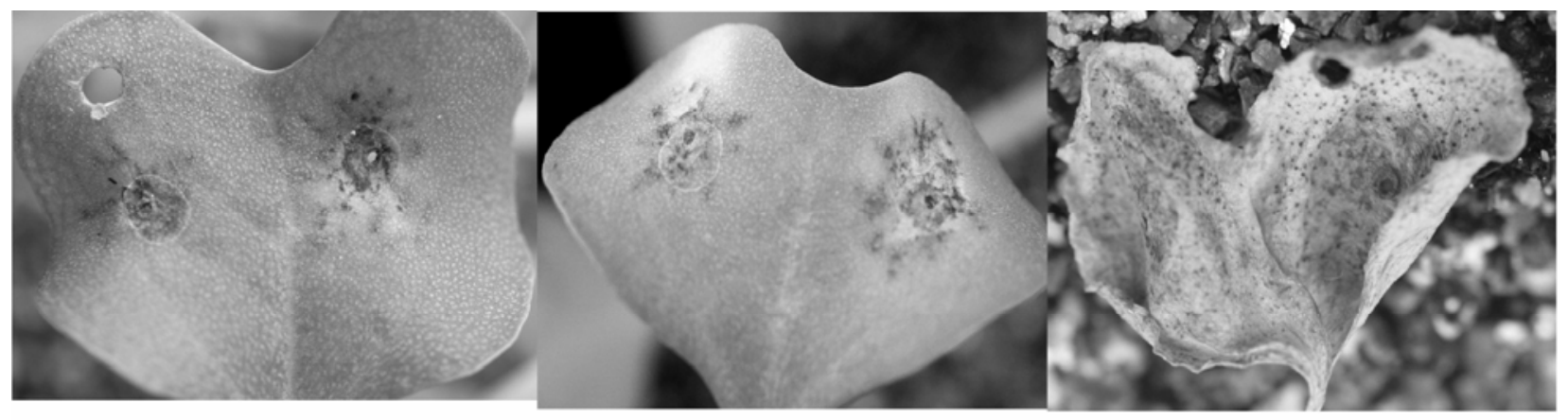

Columbus

Surpass 400

Fig. 1. Symptoms expressed 14 days postinoculation on cotyledons of winter-type (Columbus and 02.22.2.1) and spring-type (Surpass 400) oilseed rape, following inoculation with Leptosphaeria biglobosa 'occiaustralensis' isolates A21.5 (left) and A21.7 (right). Note the medium-sized lesions with patches of dark necrotic spots, typical of the L. biglobosa-B. napus interaction, on lines Columbus and 02.22.2.1 (10).

TABLE 1. List of Western Australian Leptosphaeria biglobosa isolates identified in a random sampling (set 1) and list of L. biglobosa isolates from the University of Western Australia collection (set 2) analyzed here

\begin{tabular}{|c|c|c|c|c|c|c|c|c|c|c|}
\hline \multirow[b]{2}{*}{ Isolate id. } & \multirow[b]{2}{*}{ Set of isolates } & \multicolumn{3}{|c|}{ Isolated from } & \multirow[b]{2}{*}{ Year } & \multirow[b]{2}{*}{ Site $^{\mathrm{b}}$} & \multirow[b]{2}{*}{ ITS size ${ }^{c}$} & \multicolumn{3}{|c|}{ Sequencing } \\
\hline & & Host plant & Cultivar & Organ $^{a}$ & & & & ITS & Actin & Tubulin \\
\hline A17.1 & 1 & B. napus & Grouse & $\mathrm{S}$ & 2004 & Mt B. & $580-585$ bp & $+^{\mathrm{d}}$ & $\mathrm{Nd}$ & $\mathrm{Nd}$ \\
\hline A 21.1 & 1 & B. napus & Surpass 501TT & $\mathrm{S}$ & 2003 & WH & $580-585$ bp & + & + & + \\
\hline A 21.2 & 1 & B. napus & Surpass 501TT & $\mathrm{S}$ & 2003 & WH & $580-585$ bp & + & + & + \\
\hline A 21.3 & 1 & B. napus & Surpass 501TT & $\mathrm{S}$ & 2003 & WH & $580-585 \mathrm{bp}$ & + & $\mathrm{Nd}$ & $\mathrm{Nd}$ \\
\hline A 21.4 & 1 & B. napus & Surpass 501TT & $\mathrm{S}$ & 2003 & WH & $580-585$ bp & + & + & + \\
\hline $\mathrm{A} 21.5$ & 1 & B. napus & Surpass 501TT & $\mathrm{S}$ & 2003 & WH & $580-585 \mathrm{bp}$ & + & + & + \\
\hline A 21.6 & 1 & B. napus & Surpass 501TT & $\mathrm{S}$ & 2003 & WH & $580-585 \mathrm{bp}$ & + & + & + \\
\hline A 21.7 & 1 & B. napus & Surpass 501TT & $\mathrm{S}$ & 2003 & WH & $580-585 \mathrm{bp}$ & + & + & + \\
\hline A 21.8 & 1 & B. napus & Surpass 501TT & $\mathrm{S}$ & 2003 & WH & $580-585 \mathrm{bp}$ & + & + & + \\
\hline $\mathrm{H} 1$ & 2 & B. napus & Hyola 60 & $\mathrm{~L}$ & 2002 & Mt B. & $580-585 \mathrm{bp}$ & + & $\mathrm{Nd}$ & $\mathrm{Nd}$ \\
\hline $\mathrm{H} 2$ & 2 & B. napus & Hyola 60 & $\mathrm{~L}$ & 2002 & Mt B. & $580-585 \mathrm{bp}$ & + & $\mathrm{Nd}$ & $\mathrm{Nd}$ \\
\hline $\mathrm{H} 3$ & 2 & B. napus & Hyola 60 & $\mathrm{~L}$ & 2002 & Mt B. & $580-585$ bp & + & $\mathrm{Nd}$ & $\mathrm{Nd}$ \\
\hline H5 & 2 & B. napus & Hyola 60 & $\mathrm{~L}$ & 2002 & Mt B. & $580-585 \mathrm{bp}$ & $\mathrm{Nd}$ & $\mathrm{Nd}$ & $\mathrm{Nd}$ \\
\hline 21 & 2 & B. napus & Surpass 404CL & $\mathrm{S}$ & 2003 & Mt B. & $580-585 \mathrm{bp}$ & + & $\mathrm{Nd}$ & $\mathrm{Nd}$ \\
\hline W1.1 & 2 & Wild radish & & $\mathrm{S}$ & 2003 & Mt B. & $580-585$ bp & $\mathrm{Nd}$ & $\mathrm{Nd}$ & $\mathrm{Nd}$ \\
\hline W2.1 & 2 & Wild radish & & $\mathrm{L}$ & 2003 & Mt B. & $580-585 \mathrm{bp}$ & + & $\mathrm{Nd}$ & $\mathrm{Nd}$ \\
\hline W4.2 & 2 & Wild radish & & $\mathrm{L}$ & 2003 & Mt B. & $580-585 \mathrm{bp}$ & + & $\mathrm{Nd}$ & $\mathrm{Nd}$ \\
\hline W3.1 & 2 & Wild radish & & $\mathrm{L}$ & 2003 & Mt B. & $580-585$ bp & + & $\mathrm{Nd}$ & $\mathrm{Nd}$ \\
\hline W5.1.2 & 2 & Wild radish & & $\mathrm{L}$ & 2003 & Mt B. & $580-585 \mathrm{bp}$ & $\mathrm{Nd}$ & $\mathrm{Nd}$ & $\mathrm{Nd}$ \\
\hline
\end{tabular}

${ }^{a} \mathrm{~S}$, single-ascospore isolate from stem; $\mathrm{L}$, single-conidium isolate from leaf lesions.

b Mt B., Mount Barker; WH, Wongan Hills.

${ }^{c}$ Size of the polymerase chain reaction fragment encompassing the ITS1-5.8S-ITS2 region: 580-585 bp is the size expected for L. biglobosa (5).

$\mathrm{d}+$, sequencing performed; Accession no.: AM410082 for ITS, AM410084 for actin, AM410083 for $\beta$-tubulin; Nd, not done. 
Protocols for fungal isolation, culture conditions for assessment of colony morphology on V8-agar medium, or for sporulation and for long-term storage were as reported previously $(4,28)$. Conidia suspensions were adjusted to $10^{7}$ conidia $\mathrm{ml}^{-1}$ for inoculation tests, or used at the maximum concentration for DNA extraction.

Pathogenicity tests. Seven Western Australian L. biglobosa isolates, from different geographical or plant origin (UWA 21, UWA H5, UWA W1-1, UWA A17-1, UWA A21-1, UWA A21-4, and UWA A21-8; Table 1), along with six isolates belonging to the main L. biglobosa subspecies (15): IBCN29 (L. biglobosa 'australensis'), IBCN64 (L. biglobosa 'thlaspii'), IBCN 81 (L. biglobosa 'canadensis'), IBCN48, IBCN90, and UK-MX1 (L. biglobosa 'brassicae') (Table 2) were inoculated on cotyledons of six cultivars or lines: four winter-type oilseed rape genotypes, cvs. Columbus and Darmor and lines 02.22.2.1 and 01.23.2.1, and the spring-type oilseed rape cvs. Surpass 400 and Westar. Inoculation tests and symptom scoring using the semiquantitative IMASCORE rating scale were as described by Balesdent et al. $(4,6)$. However, since the IMASCORE rating scale is devised to assess the L. maculans-Brassica sp. interaction, and can be partly inadequate for evaluating the L. biglobosa-Brassica sp. interaction, the diameter of the lesions 12 and 16 days postinoculation (dpi) was also measured. Each isolate was inoculated on at least 10 different plants and the experiment was repeated twice. Mean lesion sizes were calculated for each experiment/isolate/plant genotype combination and were analyzed using analysis of variance (ANOVA). Isolates within a subclade, or subclades, were compared using a Bonferroni test. Statistical analyses were performed using XLStat 7.5.

DNA extraction and molecular analyses. DNA was extracted from conidial suspensions using the DNeasy 96 plant kit and the Bio-Robot 3000 (Qiagen SA, Courtabeuf, France) as previously established (2). The ITS region was amplified using PN3 and PN10 primers and PCR products were separated on $1.8 \%$ agarose gels as previously established $(5,15)$. This primer pair generates a PCR fragment sized 555 to 560 bp for L. maculans and 580 to 585 bp for L. biglobosa (5). For the sequencing of ITS, actin, and $\beta$-tubulin, PCR was performed according to Mendes-Pereira et al. (15) or to Voigt et al. (27). Sequencing was performed in both directions, so that each base was read at least twice. Sequencing of PCR fragments using the ABI PRISM 310 Genetic Analyzer (5).

Phylogenetic analyses. Preliminary sequence alignments were performed using ClustalX version 1.83 (26) and included previously published ITS, actin, and $\beta$-tubulin sequences from $L$. biglobosa isolates of the species complex (Table 2) $(15,27)$. Alignments were checked manually for ambiguities and adjusted when necessary using GeneDoc 2.6.002 (19). Following manual editing, genetic distances were calculated and neighbor-joining (NJ) trees were prepared using the Draw NJ tree option of ClustalX. This option uses Kimura's two-parameter method for estimating evolutionary distances and implements the NJ algorithm of Saitou and Nei. Parsimony analyses were performed using the phylogenetic analysis using parsimony package (PAUP) (4.0b2; Sinauer Associates, Inc., Enfield, NH) (25). Heuristic searches for the most parsimonious trees were conducted with random stepwise addition and branch-swapping algorithm using tree-bisectionreconnection (TBR). All characters were unordered and equally weighted, and analyses of data sets were performed with gap sets as either missing data or fifth base. For each analysis, clade stability was assessed using 1,000 bootstrap replications either with ClustalX for NJ trees or with PAUP* for parsimony analyses. All trees were rooted using L. maculans 'brassicae' IBCN80 (Leroy) as an outgroup (Table 2).

For each individual data set, trees were first visually compared for robustness of nodes. The data sets were then concatenated and partitioned by genetic locus. The partition-homogeneity test $(\mathrm{P}-\mathrm{H}$ implemented in PAUP*) was used to estimate data partition combinability. The data sets were analyzed pairwise and in total using maximum parsimony criteria as described above. Alignment and trees were submitted to Treebase (accession SN3600).

\section{RESULTS}

ITS phylogeny suggests $L$. biglobosa isolates are present in Western Australia and belong to a novel subclade. ITS amplification of all atypical Leptosphaeria isolates from Western Australia generated a PCR fragment whose size, ranging between 580

TABLE 2. List and characteristics of additional Leptosphaeria isolates used in this study for phylogenetic and/or pathogenicity analyses

\begin{tabular}{|c|c|c|c|c|c|c|}
\hline \multirow[b]{2}{*}{ Isolate name } & \multirow[b]{2}{*}{ Species } & \multirow[b]{2}{*}{ Subclade } & \multirow{2}{*}{$\begin{array}{l}\text { Geographical } \\
\text { origin }\end{array}$} & \multicolumn{3}{|c|}{ Genebank accession numbers } \\
\hline & & & & ITS $^{\mathrm{a}}$ & $\beta$-tubulin ${ }^{\mathrm{b}}$ & Actin $^{b}$ \\
\hline Leroy (IBCN80) & maculans & 'brassicae' & Canada & AJ550883 & AY749018 & AY748970 \\
\hline IBCN84 & maculans & 'lepidii' & Canada & AJ550890 & AY749020 & AY748972 \\
\hline IBCN29 & biglobosa & 'australensis' & Australia & AJ550869 & AY749000 & AY748952 \\
\hline IBCN30 & biglobosa & 'australensis' & Australia & AJ550871 & na & na \\
\hline IBCN91 & biglobosa & 'australensis' & USA & AJ550870 & AY749001 & AY748953 \\
\hline CBS298 & biglobosa & 'brassicae' & nk & AJ550862 & na & na \\
\hline Gui2a2 & biglobosa & 'brassicae' & China & AJ550858 & na & na \\
\hline Gui2b3 & biglobosa & 'brassicae' & China & AJ550861 & na & na \\
\hline IBCN38 & biglobosa & 'brassicae' & Europe & AJ550860 & na & na \\
\hline IBCN48 & biglobosa & 'brassicae' & Europe & AJ550859 & na & na \\
\hline IBCN49 & biglobosa & 'brassicae' & Europe & AJ550864 & na & na \\
\hline IBCN89 & biglobosa & 'brassicae' & Canada & AJ550863 & AY748997 & AY748949 \\
\hline IBCN90 & biglobosa & 'brassicae' & Canada & na & AY748998 & AY748950 \\
\hline IBCN93 & biglobosa & 'brassicae' & USA & AJ550857 & AY748999 & AY748951 \\
\hline $\mathrm{Pl}-53$ & biglobosa & 'brassicae' & Europe & AJ550865 & na & na \\
\hline UK-MX1 & biglobosa & 'brassicae' & Europe & na & na & na \\
\hline IBCN63 & biglobosa & 'canadensis' & Canada & AJ550868 & AY749004 & AY748956 \\
\hline IBCN82 & biglobosa & 'canadensis' & Canada & AJ550866 & AY749006 & AY748958 \\
\hline NB2 & biglobosa & 'canadensis' & Canada & M96383 & na & na \\
\hline Unity (IBCN81) & biglobosa & 'canadensis' & Canada & AJ550867 & AY749005 & AY748957 \\
\hline IBCN83 & biglobosa & 'erysimii’ & Canada & AJ550872 & AY749008 & AY748960 \\
\hline IBCN64 & biglobosa & 'thlaspii' & Canada & na & AY749009 & AY748961 \\
\hline CBS 303 & biglobosa & 'thlaspii' & Europe & AJ550892 & na & na \\
\hline IBCN65 & biglobosa & 'thlaspii' & Canada & AJ550891 & AY749010 & AY748962 \\
\hline
\end{tabular}

a Accession numbers according to Mendes-Pereira et al. (15).

b Accession numbers according to Voigt et al. (27). na, not available; nk, not known. 
and $585 \mathrm{bp}$, was consistent with what was expected for L. biglobosa, but not for L. maculans (5) (Table 1). Sequencing and alignment of the ITS of 16 of these isolates confirmed that size of their ITS1-5.8S-ITS2 sequence, $496 \mathrm{bp}$, was identical to that found for all other L. biglobosa isolates except L. biglobosa 'thlaspii' (497 bp) and 'erysimii' (499 bp) (15). In addition, 100\% nucleotidic identity was observed between ITS sequences of the Western Australian isolates (deposited as accession no. AM410082) (Fig. 2).

These 16 ITS sequences were submitted to phylogenetic analyses by comparison with the previously published ITS sequences from other members of the species complex (15) (Tables 1 and 2). The ratio of nucleotidic identity with isolates from other L. biglobosa subclades ranged between 93.57 and $99.40 \%$. Surprisingly, the highest identity was not found with isolates of the L. biglobosa 'australensis' subclade, but with isolates of the L. biglobosa 'canadensis' subclade, with only three polymorphic nucleotides out of 496. Alignment of the ITS1-5.8S-ITS2 sequences resulted in a data set of 501 characters, of which 60 (12\%; gaps treated as missing data) or 68 (13.6\%; gaps treated as 5th base) were parsimony informative. Parsimony analysis resulted in two most parsimonious trees (MPT) whether gaps were treated as missing or as fifth base (Fig. 2). As already described (15), parsimony trees resulted in a strongly supported clade containing all L. biglobosa isolates, and clearly separated from the two L. maculans subclades (15) (Fig. 2). The L. biglobosa 'thlaspii' isolates were separated from a strongly supported subclade containing all other L. biglobosa subclades. These latter were separated into two subclades: L. biglobosa 'australensis' and L. biglobosa 'erysimii' isolates on the one hand, and L. biglobosa 'brassicae', L. biglobosa 'canadensis', and L. biglobosa isolates from Western Australia, on the other hand. L. biglobosa 'brassicae' was separated from a subclade containing the L. biglobosa 'canadensis' and L. biglobosa isolates from Western Australia. These two formed a polytomy from which a single L. biglobosa 'canadensis' clade emerged (Fig. 2).

$\mathrm{NJ}$ trees were similar to those obtained in parsimony analysis, with L. biglobosa 'canadensis' and L. biglobosa isolates from Western Australia forming monophyletic clades, and a strong bootstrap support for the separation between the two subclades (data not shown). All these data confirm that the atypical Leptosphaeria isolates from Western Australia belong to the L. biglobosa species, but may form a distinct subclade from all subclades described to date.

Multiple gene genealogies confirm the belonging to a novel subclade. The actin and $\beta$-tubulin fragments of seven $L$. biglobosa isolates were PCR-amplified and sequenced (Table 1). For both fragments, no sequence polymorphism was observed between the isolates. The actin fragment (deposited as accession AM410084) included a 50 bp predicted intron, as already described for all members of the L. maculans - L. biglobosa species complex (27). Similarly, the $\beta$-tubulin fragment analyzed (deposited as accession no. AM410083) encompassed a 61 bp intron similar in size to that of L. biglobosa 'canadensis' (27), but one bp smaller than the $\beta$-tubulin intron of all other members of the L. biglobosa clade (27). The pairwise sequence identity for actin between the sequence of Western Australian L. biglobosa isolates and individual members of the species complex ranged from 97.09 to $99.12 \%$ for the exon sequence and from 80.00 (between Western Australian L. biglobosa isolates and L. biglobosa 'australensis' or 'erysimii') to $96.00 \%$ (between Western Australian L. biglobosa isolates and L. biglobosa 'canadensis') for the intron sequence (data not shown). A similar high identity was obtained for the $\beta$-tubulin fragment, ranging from 95.76 (between Western Australian L. biglobosa isolates and L. biglobosa 'thlaspii') to 99.41\% (between Western Australian L. biglobosa isolates and L. biglobosa 'canadensis') for the exon sequence and from $78.55 \%$ (between Western Australian L. biglobosa isolates and

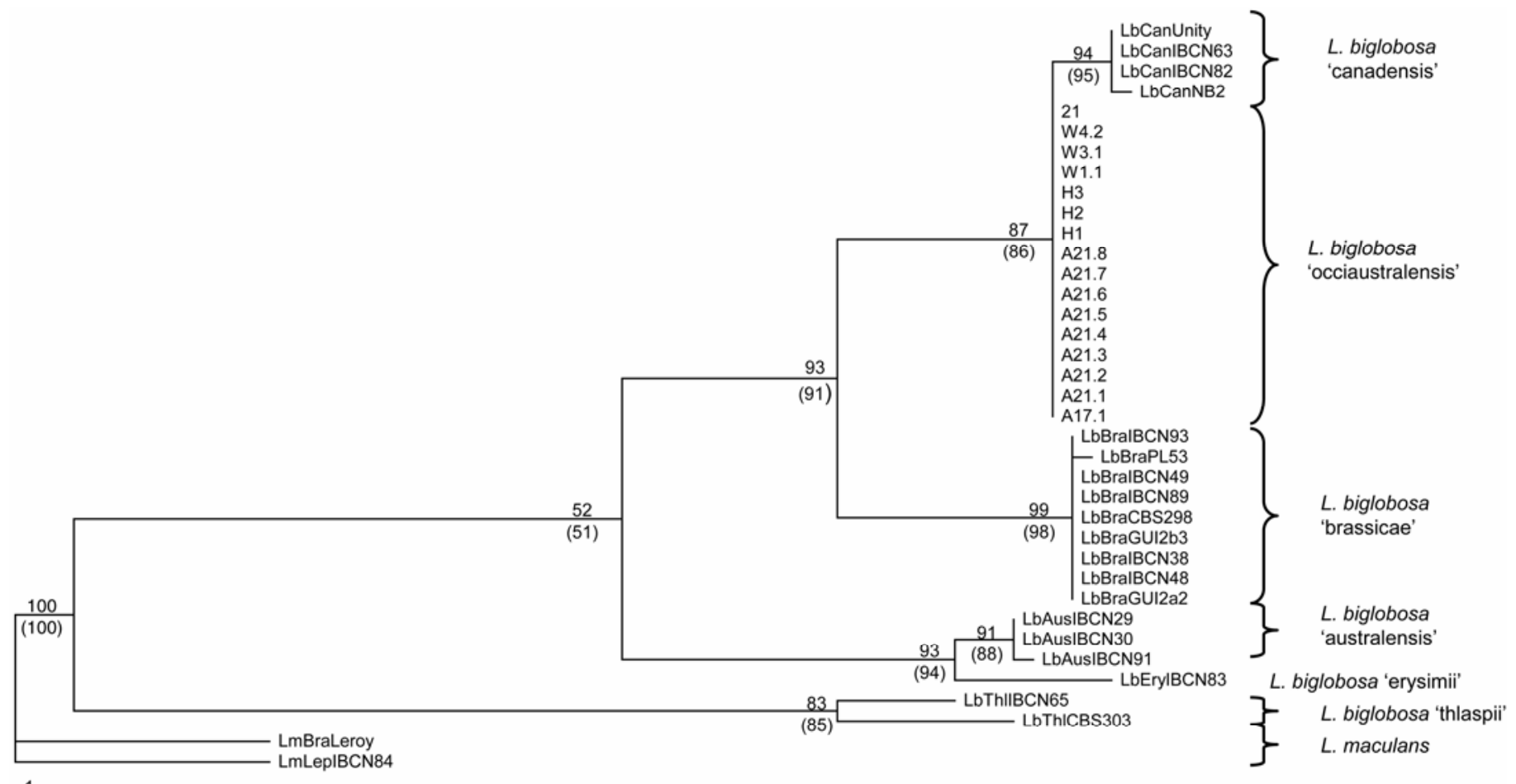

1

Fig. 2. Phylogeny analysis of the Leptosphaeria maculans-L. biglobosa species complex based on parsimony analysis of the internal transcribed spacer 1 (ITS1)5.8S-ITS2 sequence data. The tree is one of the two most equally parsimonious generated. L. maculans 'brassicae' (LmBraLeroy) and L. maculans 'lepidii' (LmLepIBCN84) are included as outgroups. Bootstrap values (1,000 replications) are indicated as percentages above the node for analyses where gaps are treated as a fifth base, and below the nodes in parenthesis for analyses where gaps are treated as missing data. The length of the tree is $168 \mathrm{steps}(\mathrm{CI}=0.90, \mathrm{RI}=0.92)$ for gaps treated as fifth base or 127 steps $(\mathrm{CI}=0.87, \mathrm{RI}=0.91)$ for gaps treated as missing data. The isolates and sequence references are described in Table 2 . Sequence data for the reference isolates are from Mendes-Pereira et al. (15). 
L. biglobosa 'thlaspii') to $86.18 \%$ (between Western Australian L. biglobosa isolates and L. biglobosa 'australensis') for the intron sequence.

Phylogenetic analyses using parsimony or distance resulted in trees of similar topologies with higher bootstrap values for NJ trees as compared with parsimony trees. Alignment of the actin sequences resulted in a data set of 838 characters of which 49 $(5.8 \%)$ were parsimony-informative. Parsimony analysis resulted in one MPT (steps $=121, \mathrm{CI}=0.88, \mathrm{RI}=0.92$ ) with the same clade/subclade separation as with the ITS data set (Fig. 3). Alignment of the $\beta$-tubulin sequences resulted in a data set of 912 characters with 50 (gaps $=$ missing, $5.5 \%)$ or 52 (gaps $=5$ th base, $5.7 \%$ ) parsimony informative characters. Parsimony analyses resulted in 5 MPT (gaps $=$ missing, steps $=137, \mathrm{CI}=088, \mathrm{RI}=$ 0.89 ) or 4 MPT (gaps $=5$ th base, step $=151, \mathrm{CI}=0.88, \mathrm{RI}=$ 0.89) (data not shown). The Western Australian L. biglobosa isolates still formed a strongly supported subclade, and all usual subclades were strongly supported. However, the insufficient bootstrap supports could indicate occurrence of L. biglobosa from Western Australia as a sister subclade to (i) a subclade comprising all the other L. biglobosa isolates, except L. biglobosa 'thlaspii', (ii) a subclade comprising L. biglobosa 'australensis' and 'erysimii', or (iii) a subclade comprising L. biglobosa 'brassicae' and 'canadensis' (data not shown). This uncertainty was mainly due to the highly polymorphic $\beta$-tubulin intron sequences since alignment of the $\beta$-tubulin exon sequences (data set of 873 characters with $37(4.2 \%)$ parsimony informative characters) resulted in only two MPT ( steps $=104, \mathrm{CI}=0.89, \mathrm{RI}=0.88$ ) with the same supported nodes as for the ITS or actin data sets (data not shown).

As already shown for the actin- $\beta$-tubulin data sets (27), partition-homogeneity tests gave the statistical support that data sets could be combined either two by two (actin- $\beta$-tubulin: $P=0.58$,
ITS- $\beta$-tubulin: $P=0.32$, actin-ITS: $P=1.0)$ or as a whole $(P=$ 0.38 ). Combined data sets confirmed the analyses using single gene sequence (Fig. 4). Phylogenetic analyses using the three concatenated sequences resulted in NJ or parsimony trees of similar topologies. Alignment of the concatenated sequences resulted in a data set of 2,251 characters of which 115 (5.1\%; gaps = missing) or $118(5.2 \%$, gaps $=5$ th base $)$ were parsimony informative. Parsimony analysis resulted in two MPT (gaps $=5$ th base $:$ steps $=385, \mathrm{CI}=0.89, \mathrm{RI}=0.88$; gaps $=$ missing $:$ steps $=335$, $\mathrm{CI}=0.89, \mathrm{RI}=0.88)$ with the same supported nodes as with the ITS (Fig. 2) or actin data set (Fig. 3) but with stronger bootstrap support (Fig. 4). These essentially confirmed that the Western Australian L. biglobosa isolates formed a strongly supported subclade closely related but distinct from L. biglobosa "canadensis' isolates (Fig. 4). Due to their geographic origin, isolates of this subclade were termed L. biglobosa 'occiaustralensis' .

Pathogenicity to oilseed rape of $L$. biglobosa 'occiaustralensis'. In order to compare the pathogenicity of L. biglobosa 'occiaustralensis' with that of members of the other L. biglobosa subclades, a cotyledon-inoculation experiment was conducted twice with seven L. biglobosa 'occiaustralensis' isolates along with six isolates belonging to the main L. biglobosa subclades. An overall higher disease severity was observed in the first experiment compared to the second one (Fig. 5, Table 3). However, the quantitative assessment of pathogenicity, based on lesion diameter, was highly reproducible between the two experiments (Pearson's correlation $r=0.833, P<0.001$ ) and isolates or groups of isolates were classified similarly in the two experiments (Fig. 5, Table 3). ANOVA of mean lesion diameters revealed a significant effect of the group to which each isolate belongs $(F=$ 116.631, $P<0.0001)$. L. biglobosa 'australensis', L. biglobosa 'thlaspii', and L. biglobosa 'canadensis' isolates always ranked as weakly virulent, and basically were unable to cause symptoms on

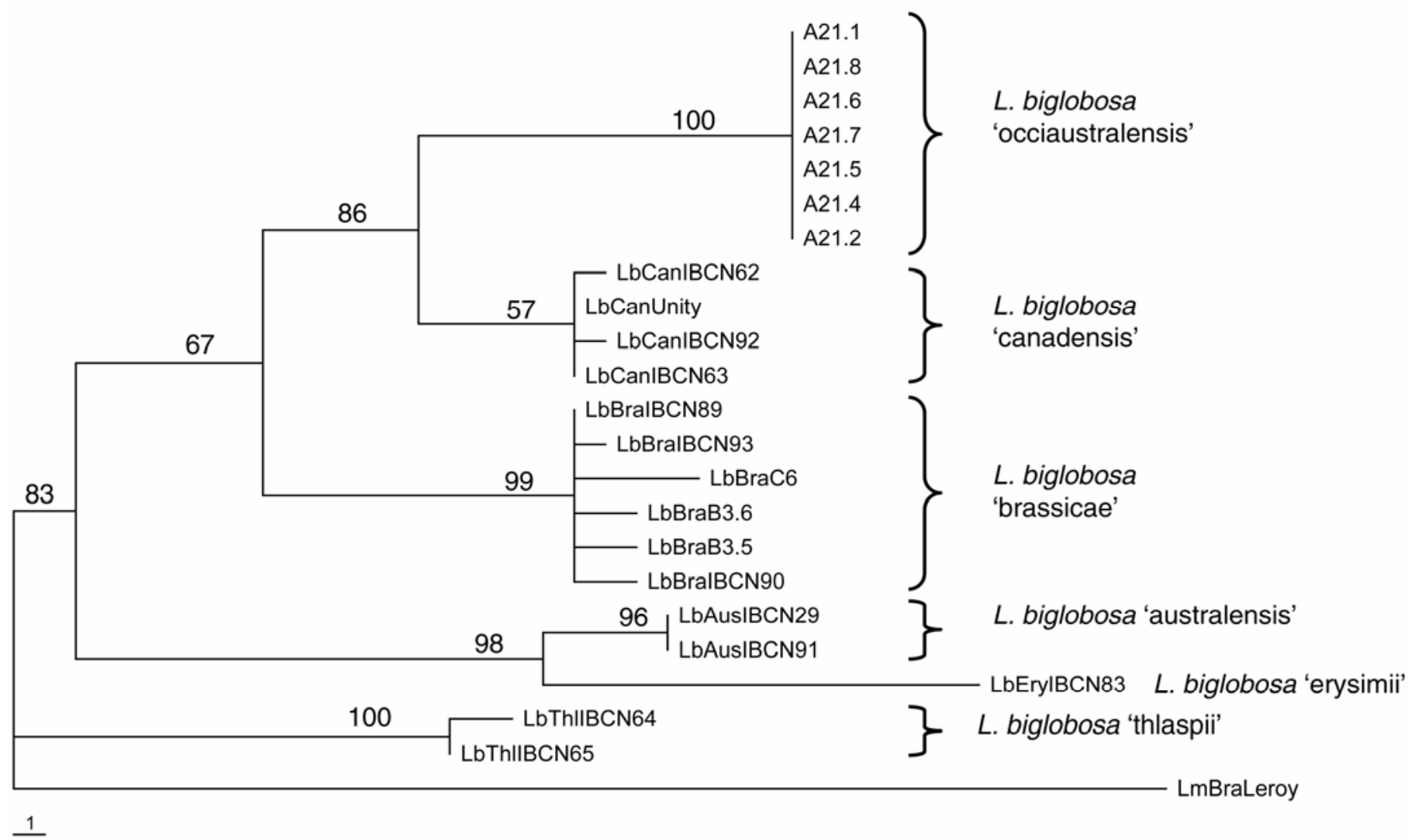

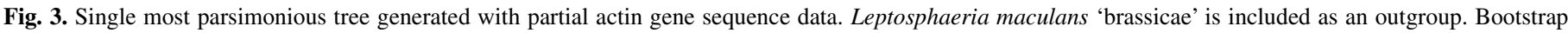

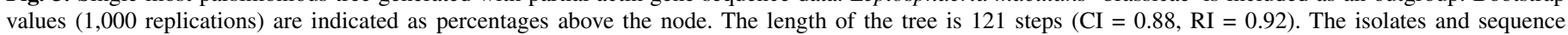
references are described in Tables 1 and 2. Sequence data for the reference isolates are from Voigt et al. (27). 
all tested B. napus genotypes (Fig. 5, Table 3). All the L. biglobosa 'brassicae' always ranked as the most virulent on all cultivars (Fig. 5, Table 3). L. biglobosa 'occiaustralensis' isolates were significantly less pathogenic than the L. biglobosa 'brassicae' isolates, but more pathogenic than other L. biglobosa isolates, whatever the cultivar or line used (Fig. 5, Table 3). ANOVA of mean lesion diameters also detected significant differences in aggressiveness between isolates within the L. biglobosa 'occiaustralensis' subclade $(F=3.92, P<0.0001)$. For these isolates a strong plant genotype effect was also detected $(F=57.849, P<$ $0.0001)$. Plant genotype ranking was not significantly correlated between the two groups of isolates (Spearman's correlation $r=$ $0.600, P=0.206$, NS). Particularly, the susceptibility of $\mathrm{cv}$. Surpass 400 was high in the L. biglobosa 'occiaustralensis' subclade, compared to other winter B. napus lines; Surpass 400 was classified, along with Westar, as significantly more susceptible than the four other lines inoculated with L. biglobosa 'occiaustralensis' isolates (Table 4, Fig. 1).

\section{DISCUSSION}

In previous studies, L. biglobosa was shown to exhibit extreme diversity as compared to $L$. maculans, with five distinct subclades that were hypothesized to be distinct subspecies (15). In this respect, it was suggested that L. biglobosa has been subjected to numerous levels of reproductive isolation, either linked to host specificity or geographic isolation that lead with time to these probable pre-speciation events (15). The data obtained here further confirm the high polymorphism of the L. biglobosa species, with the discovery of a sixth subclade, L. biglobosa 'occiaustralensis', more related to L. biglobosa 'canadensis' than to other subclades of L. biglobosa, but nevertheless distinct from it.
The first paper suggesting L. biglobosa may exist in Australia was that of Koch et al. (12) describing four Australian 'PG1' (one former denomination of L. biglobosa) obtained from B. oleracea and $B$. juncea, and identified using pigment production, patho-

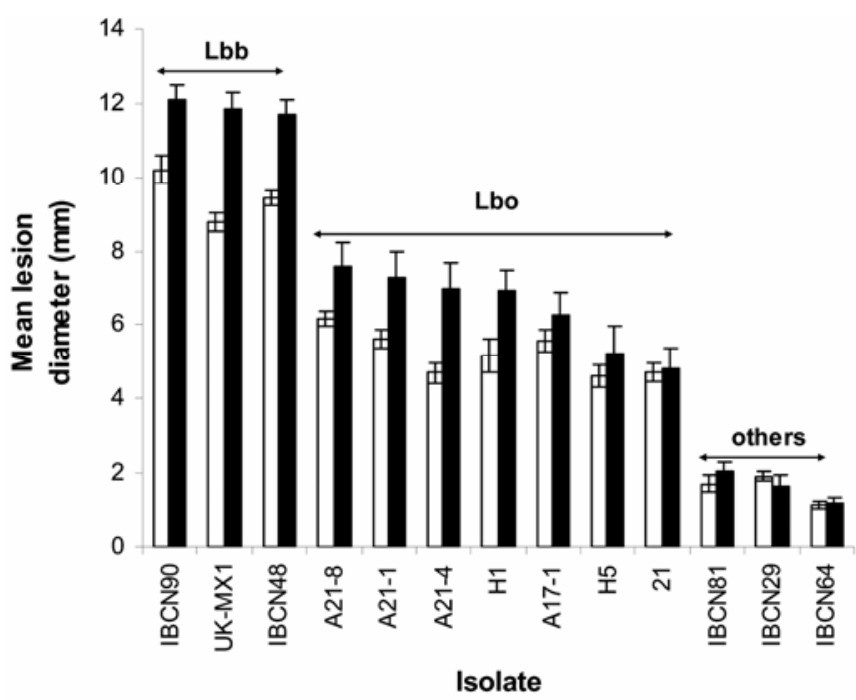

Fig. 5. Pathogenicity assessment of 13 Leptosphaeria biglobosa isolates belonging to five distinct subclades. Lbb, three L. biglobosa 'brassicae'; Lbo, seven L. biglobosa 'occiaustralensis'; others, three isolates from other subclades (Tables 1 and 2 provide more information on the isolates) were inoculated on six B. napus genotypes. Vertical bars indicate mean lesion diameters over all six B. napus genotypes in the first (black bars) and second (white bars) experiments. Vertical lines represent standard deviations.

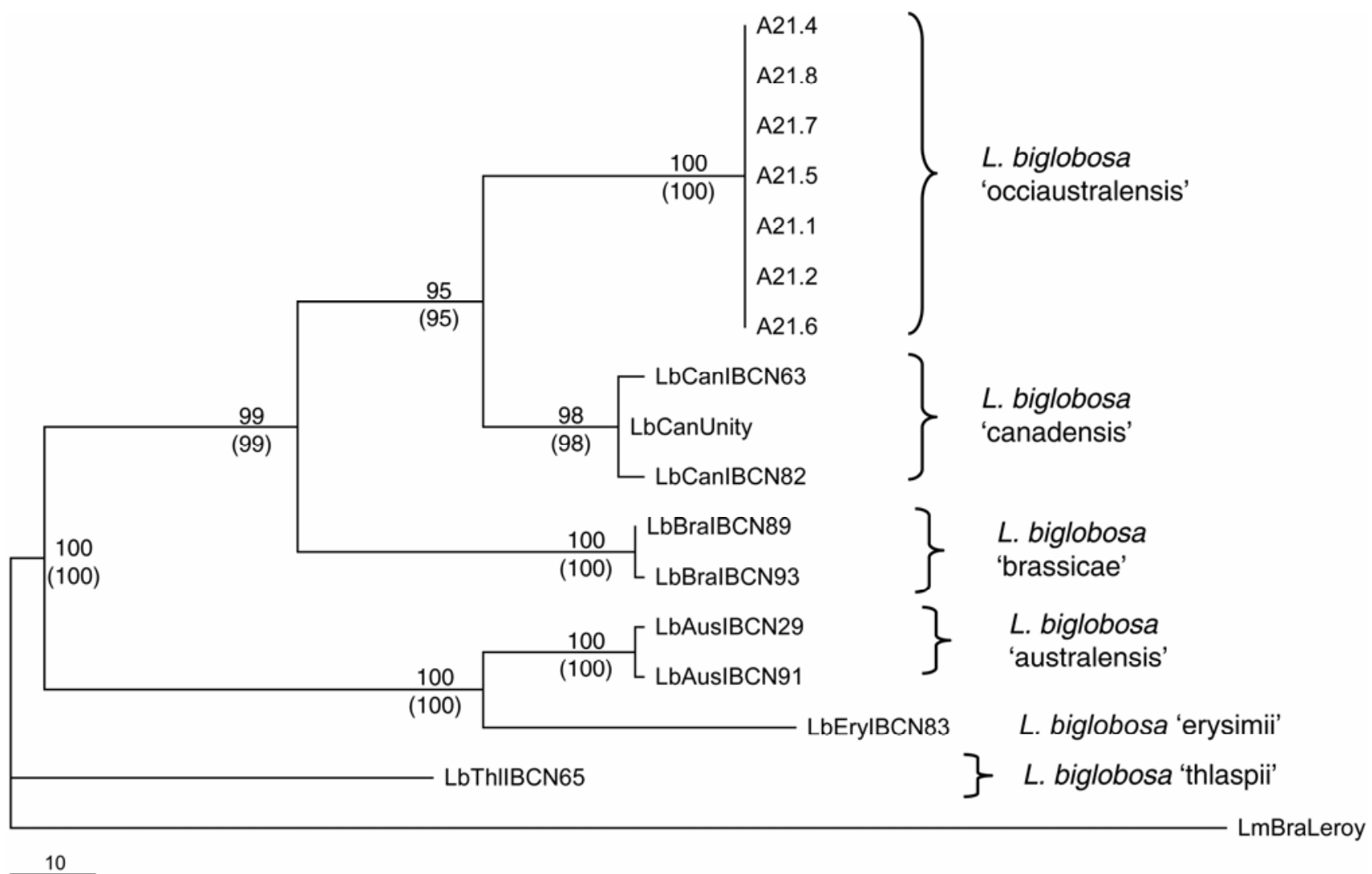

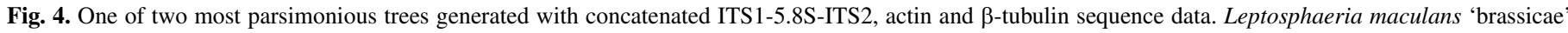

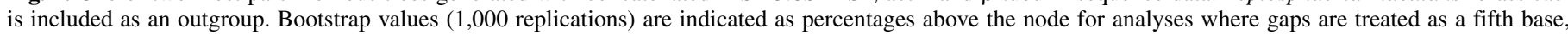

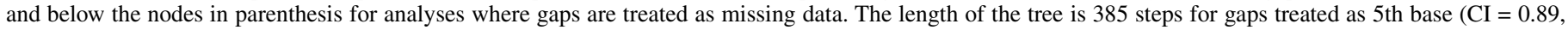

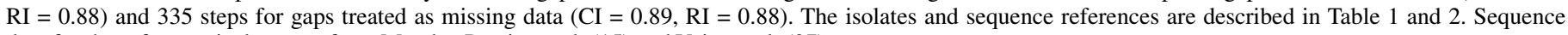
data for the reference isolates are from Mendes-Pereira et al. (15) and Voigt et al. (27). 
genicity, and restriction fragment length polymorphism (RFLP) analyses. At the same time, Mengistu et al. (16) described five Australian 'PG1' isolates, that may partly be identical to those described by Koch et al. (12), identified on the basis of their pathogenic behavior. Plummer et al. (20) were the first to report isolation of L. biglobosa from oilseed rape (B. napus) in Victoria, with identification, using numerous criteria, of $5 \mathrm{~L}$. biglobosa isolates originating from only two pseudothecia. Finally, more recently, Sosnowski et al. (24) described two L. biglobosa isolates from B. napus in South Australia, which they characterized mainly with pathogenicity and pigment production traits. In contrast to these reports, most of the large-scale analyses of blackleg populations in Australia failed to identify the presence of L. biglobosa. Extensive surveys have been carried out on the population of the blackleg pathogen since 1971 and did not show any evidence of L. biglobosa in Western Australia (23). Similarly, the analysis of 100 isolates obtained from B. napus stubbles Australia-wide did not indicate the presence of any L. biglobosa isolate (7). This led West et al. (30) to conclude that L. biglobosa was virtually absent from Australia. In this respect, the finding of $5.2 \%$ L. biglobosa in our Western Australia sampling, in two distinct locations, was unexpected. Many of the L. biglobosa isolates obtained here were from Mount Barker, whereas Ballinger and Salisbury (7) did not find any L. biglobosa isolates in their Mount Barker sampling. It seems therefore that L. biglobosa isolates were either absent or present only at nondetectable levels during the 1990s in Western Australia.

In France, $21 \%$ of the isolates sampled in the field from leaves of the first Rlm1 oilseed rape cultivars, at a time when this

TABLE 3. Comparison of aggressiveness of different subclades of Leptosphaeria biglobosa, as measured by the mean lesion diameter expressed on Brassica napus cotyledons

\begin{tabular}{|c|c|c|c|c|c|}
\hline L. biglobosa subclade ${ }^{a}$ & Repeat $^{\mathrm{b}}$ & $\begin{array}{l}\text { Mean lesion } \\
\text { diameter }^{\mathrm{c}}\end{array}$ & \multicolumn{3}{|c|}{ Homogeneous groups ${ }^{\mathrm{d}}$} \\
\hline \multirow[t]{2}{*}{ Lbb } & 1 & 11.87 & A & & \\
\hline & 2 & 9.50 & B & & \\
\hline \multirow[t]{2}{*}{ Lbo } & 1 & 6.47 & & $\mathrm{C}$ & \\
\hline & 2 & 5.21 & & $\mathrm{C}$ & \\
\hline \multirow[t]{2}{*}{ Others } & 1 & 1.64 & & & $\mathrm{D}$ \\
\hline & 2 & 1.61 & & & $\mathrm{D}$ \\
\hline
\end{tabular}

a Lbb, L. biglobosa 'brassicae' subclade (IBCN48, IBCN90, and UK-MX1); Lbo, L. biglobosa 'occiaustralensis' subclade (Western Australian isolates 21, H5, H1, A17.1, A21.1, A21.4, and A21.8); (others) groups L. biglobosa 'australensis' (IBCN29), L. biglobosa 'thlaspii' (IBCN64), and L. biglobosa 'canadensis' (IBCN81).

b Two independent experiments are shown.

${ }^{c}$ Data represent average lesion size $(\mathrm{mm})$ caused by isolates of a given group and for a given experiment on all six B. napus lines tested 12 days postinoculation.

d Groups with the same letter are not significantly different (Bonferroni test, $5 \%$ level). resistance was effective against the local populations of $L$. maculans, belonged to the L. biglobosa species, whereas the proportion of L. biglobosa recovered from cultivars susceptible to L. maculans was only $2.6 \%$ (1). The exclusion of L. maculans by the resistance gene and the scarcity of leaf lesions on resistant genotypes strongly enhanced the probability to recover isolates causing atypical symptoms (i.e., L. biglobosa) (1). A similar situation probably explains the sudden recovery of L. biglobosa in Mount Barker in the 2002 to 2004 samplings, compared with samplings performed before 1996, due to recovery of isolates on cultivars with efficient, single-gene based resistance derived from $B$. rapa sp. sylvestris or on wild radish, known to be resistant to $L$. maculans $(13,14)$. Accordingly, L. biglobosa isolates were absent from the large-scale sampling from leaves of the highly susceptible cv. Westar (M. H. Balesdent and M. J. Barbetti, unpublished data). It is noteworthy that the 'occiaustralensis' subclade was recorded only after the collapse of single-dominant gene-based resistance, derived from the $B$. rapa sp. sylvestris, which was widely deployed following the release of these cvs from 2000 onwards (23).

One unexpected finding of our work was the close relatedness of L. biglobosa isolates from Western Australia with the L. biglobosa 'canadensis' subclade rather than with the previously identified L. biglobosa 'australensis' clade. L. biglobosa is a very diverse species with 6 phylogenetic subclades represented in collections. However, only L. biglobosa 'brassicae' has been investigated at a wide geographical scale (i.e., Europe) and shown to be extremely monomorphic at this scale (21). In contrast, we virtually have no information on the representativeness of the L. biglobosa 'canadensis' subclade at the American continent scale, with only 6 isolates available in the IBCN collection, all coming from Saskatchewan. The same applies for the L. biglobosa 'australensis' subclade at the Australian scale, with only the five isolates obtained by Plummer et al. (20) in Victoria assigned to this clade along with isolate IBCN91 from the United States (15). The relative importance of L. biglobosa 'australensis' as compared to L. biglobosa 'occiaustralensis' in Australia is therefore difficult to evaluate. Previous reports on L. biglobosa isolates from Australia by Koch et al. (12) and Sosnowski et al. (24) seem to indicate that the Australian L. biglobosa isolates they analyzed were more related to L. biglobosa 'canadensis' than to L. biglobosa 'australensis'. Of the four Australian L. biglobosa isolates described by Koch et al. (12), only one was compared with a worldwide collection of isolates using RFLP. The RFLP profile grouped this isolate with the reference L. biglobosa 'canadensis' isolate Unity (IBCN81), and clearly separated it from the L. biglobosa 'australensis' reference isolate PHW126 (=IBCN91). However, due to the use of two different discrimination methods (RLFP [12] versus sequencing [15,27, this study]), it is not possible to conclude whether the Australian L. biglobosa analyzed by Koch et al. (12) belongs to the L. biglobosa 'canadensis' subclade or if it could have belonged to the 'occiaustralensis' subclade. While the

TABLE 4. Comparison of susceptibility of six differential Brassica napus lines to Leptosphaeria biglobosa 'brassicae' and 'occiaustralensis' isolates following cotyledon inoculation

\begin{tabular}{|c|c|c|c|c|c|}
\hline \multicolumn{3}{|c|}{ L. biglobosa 'brassicae' } & \multicolumn{3}{|c|}{ L. biglobosa 'occiaustralensis' } \\
\hline B. napus line & Mean lesion diameter ${ }^{\mathrm{a}}$ & Groups $^{\mathrm{b}}$ & B. napus line & Mean lesion diameter ${ }^{\mathrm{c}}$ & Groups $^{\mathrm{b}}$ \\
\hline 01.23.2.1 & 10.93 & A & Westar & 7.16 & A \\
\hline Westar & 10.00 & $\mathrm{AB}$ & Surpass 400 & 6.64 & A \\
\hline Surpass 400 & 9.12 & B & 01.23 .2 .1 & 5.46 & B \\
\hline Columbus & 9.06 & B & Columbus & 3.73 & $\mathrm{C}$ \\
\hline Darmor & 8.73 & B & Darmor & 2.66 & $\mathrm{D}$ \\
\hline
\end{tabular}

a Values are mean diameter $(\mathrm{mm})$ of lesions developed following inoculation of three L. biglobosa 'brassicae' isolates (IBCN48, IBCN90, UK-MX1), each on at least 10 plants per plant genotype, 12 days postinoculation (dpi).

${ }^{\mathrm{b}}$ In a column, B. napus lines with the same letter are not significantly different (Bonferroni test, $5 \%$ level).

' Values are mean diameter of lesions developed following inoculation of seven L. biglobosa 'occiaustralensis' isolates (21, H5, H1, A17.1, A21.1, A21.4, and A21.8), each on at least 10 plants per plant genotype, 12 dpi. 
two L. biglobosa isolates obtained by Sosnowski et al. (24) were mostly analyzed using pathogenicity and morphological criteria, the authors mentioned that ITS sequence of these isolates showed "a high degree of similarity (i.e. only two or three single base changes) to published sequences for avirulent isolates (18)". Morales et al. (18) sequenced the ITS region of only L. biglobosa 'canadensis' isolates (including IBCN81) or of the quite different L. biglobosa 'thlaspii' isolates. The results from Sosnowski et al. (24) are strongly reminiscent of our own finding that only three bases of the ITS1-5.8S-ITS2 are polymorphic between L. biglobosa 'canadensis' and 'occiaustralensis' isolates, whereas 18 bases are polymorphic between L. biglobosa 'australensis' and 'occiaustralensis'. This strongly suggests that L. biglobosa 'occiaustralensis' isolates may have been already found in Australia. Our own findings suggest that L. biglobosa 'occiaustralensis' may be more common than L. biglobosa 'australensis' isolates, at least in parts of Western Australia. This may occur as a consequence of early rapeseed production in Australia being established in the mid 1960s with varieties introduced from Canada (22), possibly introducing seed-transmitted L. biglobosa from Canada. In that event, the consistent polymorphism between L. biglobosa 'canadensis' and 'occiaustralensis' subclades could indicate either transmission of a subpopulation, still undescribed in Canada, of the L. biglobosa 'canadensis' clade or a very rapidly evolving subgroup following geographic isolation in Australia. Extensive surveys have now to be performed throughout Australia and Canada to evaluate, at the country scale, the level of polymorphism of L. biglobosa and the real extent of L. biglobosa 'australensis' versus 'occiaustralensis' in Australia.

Finally, the distinction between the L. biglobosa 'australensis' and L. biglobosa 'canadensis' subclades was not only substantiated by molecular criteria, but also by pathogenic behavior, with the L. biglobosa 'occiaustralensis' isolates always significantly more aggressive than L. biglobosa 'canadensis' and 'australensis' in cotyledon-inoculation tests. The L. biglobosa 'australensis', L. biglobosa 'thlaspii', and L. biglobosa 'canadensis' representative isolates we used were shown here to be only weakly pathogenic on a series of oilseed rape genotypes, in accordance with other reports $(12,17,20)$. In contrast, all of the L. biglobosa 'brassicae' isolates produced large leaf lesions on all B. napus genotypes including winter oilseed rape genotypes such as cv. Columbus. L. biglobosa 'occiaustralensis' isolates, even though displaying a significantly higher aggressiveness to most cultivars than L. biglobosa 'australensis' and L. biglobosa 'canadensis', were only weakly pathogenic on some genotypes such as cv. Columbus. Until now, it has been a matter of debate as to whether specific gene-for-gene type interactions exist between L. biglobosa and Brassicas, as commonly found between L. maculans and Brassicas. While such differential interactions have never been found for L. biglobosa 'brassicae', the data we obtained suggest differential interactions may exist between L. biglobosa 'occiaustralensis' and B. napus. This now requires further investigation, in order to evaluate whether $L$. biglobosa 'occiaustralensis' is specifically adapted to cultivars grown in Australia, including those chosen to be resistant to L. maculans, and thus may represent a threat for canola crops in Australia.

\section{ACKNOWLEDGMENTS}

We thank L. Coudard and M. Chabirand (INRA Bioger, Versailles, France) for plant management, A. Gautier (INRA Bioger, Versailles, France) for sequencing, and the School of Plant Biology and the School of Earth and Geographical Sciences at the University of Western Australia for partial funding.

\section{LITERATURE CITED}

1. Ansan-Melayah, D., Rouxel, T., Bertrandy, J., Letarnec, B., MendesPereira, E., and Balesdent, M. H. 1997. Field efficiency of Brassica napus specific resistance correlates with Leptosphaeria maculans population structure. Eur. J. Plant Pathol. 103:835-841.

2. Attard, A., Gourgues, M., Gout, L., Schmit, J., Roux, J., Narcy, J. P., Balesdent, M. H., and Rouxel, T. 2001. Molecular characterisation and polymorphism of MinLm1, a minisatellite from the phytopathogenic ascomycete Leptosphaeria maculans. Curr. Genet. 40:54-64.

3. Balesdent, M. H., Attard, A., Kuhn, M. L., and Rouxel, T. 2002. New avirulence genes in the phytopathogenic fungus Leptosphaeria maculans. Phytopathology 92:1122-1133.

4. Balesdent, M. H., Barbetti, M. J., Li, H., Sivasithamparam, K., Gout, L., and Rouxel, T. 2005. Analysis of Leptosphaeria maculans race structure in a worldwide collection of isolates. Phytopathology 95:1061-1071.

5. Balesdent, M. H., Jedryczka, M., Jain, L., Mendes-Pereira, E., Bertrandy, J., and Rouxel, T. 1998. Conidia as a substrate for internal transcribed spacer-based PCR identification of members of the Leptosphaeria maculans species complex. Phytopathology 88:1210-1217.

6. Balesdent, M. H., Louvard, K., Pinochet, X., and Rouxel, T. 2006. A large-scale survey of races of Leptosphaeria maculans occurring on oilseed rape in France. Eur. J. Plant Pathol. 114:53-65.

7. Ballinger, D. J., and Salisbury, P. A. 1996. Seedling and adult plant evaluation of race variability in Leptosphaeria maculans on Brassica species in Australia. Aust. J. Exp. Agric. 36:485-488.

8. Cozijnsen, A. J., and Howlett, B. J. 2003. Characterisation of the matingtype locus of the plant pathogenic ascomycete Leptosphaeria maculans. Curr. Genet. 43:351-357.

9. Fitt, B. D. L., Brun, H., Barbetti, M. J., and Rimmer, S. R. 2006. Worldwide importance of phoma stem canker (Leptosphaeria maculans and $L$. biglobosa) on oilseed rape (Brassica napus). Eur. J. Plant Pathol. 114:315 .

10. Gall, C., Balesdent, M. H., Desthieux, I., Robin, P., and Rouxel, T. 1995. Polymorphism of Tox $^{0}$ Leptosphaeria maculans isolates as revealed by soluble protein and isozyme electrophoresis. Mycol. Res. 99:221-229.

11. Gout, L., Eckert, M., Rouxel, T., and Balesdent, M. H. 2006. Genetic variability and distribution of mating type alleles in field populations of Leptosphaeria maculans from France. Appl. Envir. Microbiol. 72:185191.

12. Koch, E., Song, K., Osborn, T. C., and Williams, P. H. 1991. Relationship between pathogenicity and phylogeny based on restriction fragment length polymorphism in Leptosphaeria maculans. Mol. Plant-Microbe Interact. 4:341-349.

13. Li, C. X., and Cowling, W. A. 2003. Identification of a single dominant allele for resistance to blackleg in Brassica napus 'Surpass 400'. Plant Breed. 122:485-488.

14. Li, H., Barbetti, M. J., and Sivasithamparam, K. 2005. Hazard from reliance on cruciferous hosts as sources of major gene-based resistance for managing blackleg (Leptosphaeria maculans) disease. Field Crop Res. 91:185-198.

15. Mendes-Pereira, E., Balesdent, M. H., Brun, H., and Rouxel, T. 2003. Molecular phylogeny of the Leptosphaeria maculans-L. biglobosa species complex. Mycol. Res. 107:1287-1304.

16. Mengistu, A., Rimmer, S. R., Koch, E., and Williams, P. H. 1991. Pathogenicity grouping of isolates of Leptosphaeria maculans on Brassica napus cultivars and their disease reaction profiles on rapidcycling Brassicas. Plant Dis. 75:1279-1282.

17. Morales, V. M., Jasalavich, C. A., Pelcher, L. E., Petrie, G. A., and Taylor, J. L. 1995. Phylogenetic relationship among several Leptosphaeria species based on their ribosomal DNA sequences. Mycol. Res. 99:593603.

18. Morales, V. M., Pelcher, L. E., and Taylor, J. L. 1993. Comparison of the $5.8 \mathrm{~s}$ rDNA and internal transcribed spacer sequences of isolates of Leptosphaeria maculans from different pathogenicity groups. Curr. Genet. 23:490-495.

19. Nicholas, K. B., Nicholas, H. B., and Deerfield, D. W. 1997. GeneDoc: Analysis and visualization of genetic variation. Embnew.news 4:14.

20. Plummer, K. M., Dunse, K., and Howlett, B. J. 1994. Nonaggressive strains of the Blackleg fungus, Leptosphaeria maculans, are present in Australia and can be distinguished from aggressive strains by molecular analysis. Aust. J. Bot. 42:1-8.

21. Rouxel, T., Mendes-Pereira, E., Brun, H., and Balesdent, M. H. 2004. Species complex of fungal phytopathogens: Leptosphaeria maculans- $L$. biglobosa case study. Pages 33-75 in: Plant Genome: Biodiversity and Evolution, vol. 2, Pt. A: Lower groups. A. K. Sharma and A. Sharma, eds. Science Publisher, Enfield, NH.

22. Salisbury, P. A., Ballinger, D. J., Wratten, N., Plummer, K. M., and Howlett, B. J. 1995. Blackleg disease on oilseed Brassica in Australia-A review. Aust. J. Exp. Agric. 35:665-672.

23. Sivasithamparam, K., Barbetti, M. J., and Li, H. 2005. Recurring challenges from a necrotrophic fungal plant pathogen: A case study with Leptosphaeria maculans (causal agent of blackleg disease in Brassicas) in Western Australia. Ann. Bot. 96:363-377. 
24. Sosnowski, M. R., Scott, E. S., and Ramsey, M. D. 2001. Pathogenic variation of South Australian isolates of Leptosphaeria maculans and interactions with cultivars of canola (Brassica napus). Aust. Plant Pathol. 30:45-51.

25. Swofford, D. L. 1998. PAUP*: Phylogenetic analysis using parsimony (* and other methods) Version 4.02b. Sinauer Associates, Inc., Sunderland, MA.

26. Thompson, J. D., Higgs, D. G., and Gibson, T. J. 1994. Clustal W: Improving the sensitivity of multiple sequence alignment through sequence weighting, position-specific gap penalties and weight matrix choice. Nucleic Acids Res. 22:4673-4680.

27. Voigt, K., Cozijnsen, A. J., Kroymann, J., Pöggeler, S., and Howlett, B. J. 2005. Phylogenetic relationships between members of the crucifer pathogenic Leptosphaeria maculans species complex as shown by mating type (MAT1-2), actin, and $\beta$-tubulin sequences. Mol. Phylogenet. Evol. 37:541-557.

28. West, J. S., Balesdent, M. H., Rouxel, T., Narcy, J. P., Huang, Y. J., Roux, J., Steed, J. M., Fitt, B. D. L., and Schmit, J. 2002. Colonization of winter oilseed rape tissues by $\mathrm{A} / \mathrm{Tox}^{+}$and $\mathrm{B} / \mathrm{Tox}^{0}$ Leptosphaeria maculans (phoma stem canker) in France and England. Plant Pathol. 51:311-321.

29. West, J. S., Evans, N., Liu, S., Hu, B., and Peng, L. 2000. Leptosphaeria maculans causing stem canker of oilseed rape in China. Plant Pathol. 49:800-800

30. West, J. S., Kharbanda, P. D., Barbetti, M. J., and Fitt, B. D. L. 2001. Epidemiology and management of Leptosphaeria maculans (phoma stem canker) on oilseed rape in Australia, Canada and Europe. Plant Pathol. 50:10-27. 